\title{
Bilateral intra-industry trade flows and intellectual property rights protections: Further evidence from the United Kingdom
}

\author{
Haslifah M. Hasimª,*, Nasser Al-Mawalib, Debojyoti Das ${ }^{\mathrm{c}}$ \\ a Department of Mathematical Sciences, University of Essex, United Kingdom \\ ${ }^{\mathrm{b}}$ College of Economics and Political Science, Sultan Qaboos University, Oman \\ ${ }^{\mathrm{c}}$ Indian Institute of Management Raipur, India
}

\begin{abstract}
This paper investigates the relationship between the United Kingdom's (hereafter referred as UK) bilateral intra-industry trade (IIT) and foreign intellectual property rights (IPRs) protections. The empirical investigation is based on pooled UK data and benefits from the theoretical distinction between horizontal and vertical IIT. It also estimates a gravity equation for international trade using both fixed and random effects models. We then extend the analysis by employing the GMM system for dynamic panel models. The principal findings suggest that the UK's IIT is stimulated when the level of a trading partner's IPRs and its imitative ability are considered jointly. However, when IPRs and imitation abilities are considered separately, their disparate effects are not an important factor in determining UK IIT flows.
\end{abstract}

Keywords: Intra-industry trade, international trade, intellectual property rights.

JEL classifications: F10, F14, O34.

\section{Introduction}

The question of intellectual property rights (IPRs), such as patents, trademarks, designs, and copyrights, has received increasing attention in international trade. This is especially true since the signing of the Trade-Related Aspects of Intellectual Property Rights (TRIPS) agreement that came into effect on 1 January 1995. This agreement remains the most comprehensive international agreement on IPRs to date and is binding for all members of the World Trade Organization (WTO).

Several studies have attempted to investigate the link between IPRs and trade relations. Maskus and Penubarti (1995) used OECD data to demonstrate the first empirical results of a positive link between IPRs protection and bilateral manufacturing imports. The research was further extended by Smith (1999), who studied US export data, showing that US exports reacted positively to stronger IPRs, in countries where the threat of imitation is high. Rafiquzzaman (2002) applied a methodological approach, similar to Smith's (1999), but using data from Canadian exports. The results are

\footnotetext{
* Corresponding author.

E-mail address: hhashim@essex.ac.uk.
} 
comparable to those of the aforementioned papers. Later research, by Fink and Braga (2005), also suggests a significant and positive impact on bilateral trade flows for the total non-fuel trade aggregate, however IPRs were not found to be significant for high technology trade flows. These and other recent studies (Salim, et al., 2014; Kabir and Salim, 2016) generally resemble those in the literature that have described the links between IPRs protection and bilateral trade.

Ivus (2010) analysed trade, pre- and post-TRIPS, and found that the agreement led to an increase in the value of high technology exports from developed countries into developing countries. Maskus and Yang (2013) also found that IPRs played a significant role in trade determination, especially after the implementation of TRIPS. China has made significant efforts to align its IPR laws with the requirements of TRIPS since it joined the WTO in 2001. In a recent study of that country, Awokuse and Yin (2016) found similar results, indicating that stronger IPRs in China led to an increase in its bilateral trade.

After the development of new trade theory models, in the late 1970s and 1980s, by researchers such as Krugman (1979), Lancaster (1980) and Helpman (1981), intraindustry trade (IIT) has received much more attention in the theoretical literature on international trade. Krugman (1980) emphasised that IIT occurs more often in the sophisticated manufactured goods sector than in primary goods sectors, between industrialised countries that have similar levels of economic development.

The theoretical literature on IIT generally differentiates between two categories of products: horizontal IIT (HIIT) and vertical IIT (VIIT). HIIT concerns the trade of products with the same quality, but which have distinctive characteristics that are related to style and consumers' preferences. VIIT concerns the trade of products that are the same but which differ in quality. According to Kandogan (2003), disentangling IIT into the separate components, HIIT and VIIT, gives a better account of the adjustment costs that arise from trade liberalisation or expansion.

The relevance of IIT in international trade was stressed by the OECD (2010), following an increased trend in IIT in most OECD countries, between 1997 and 2008. IIT accounts for well over $40 \%$ of the trade in manufactured goods in most developed market economies. In the UK, between 1997 and 2008, on average IIT accounted for approximately $84.3 \%$ of the total trade in manufactured goods. These statistics imply that the majority of world trade is now IIT, as opposed to inter-industry trade that has been described previously by the traditional theory of international trade.

Despite the growing importance of IIT, very few studies have attempted to investigate the effects of IPRs on IIT empirically. Al-Mawali (2005) was the first to examine the effects of IPRs on bilateral IIT flows, using data from South Africa and its trading partners. The results show that the total IIT in South Africa does not depend on partners' IPRs protection levels, but rather on the interaction between the partners' IPRs strength and their imitative capabilities. Al-Mawali (2011) later extended his study, and the more recent findings suggest that IPRs have a relatively stronger effect in the case of IIT than for inter-industry trade. This could be explained by the fact that conducting IIT implies that the trading partners have similar industrial patterns and bases, and 
hence, the presence of IPRs is relatively more important than when two trading partners merely conduct IIT.

As a large part of world trade consists of IIT and because the importance of IPRs is growing in international trade, it is important to investigate the relationship between bilateral IIT flows and IPRs protection. For this reason, we extend the work of AlMawali $(2005,2011)$ in this paper to examine the relationship between the level of IPRs protection and bilateral IIT flows, focussing on the trade of machinery and transport equipment between the UK and its trading partners. Our data analysis is based on the theoretical distinction between HIIT and VIIT.

This study estimates a gravity equation for international trade within the context of static models, i.e., fixed and random effects models. Due to the endogeneity problems of some explanatory variables that might arise in the static models, as a comparative measure, we then extend the analysis by employing the GMM system (GMM-SYS) for dynamic panel models that are used in the trade literature (for example, see Felbermayr (2005); Fukase (2010); Soukiazis and Antunes, (2011)). In the context of IIT, the dynamic analysis using the GMM-SYS was introduced by Faustino and Leitão (2007), and has been use in other recent studies, e.g., Phan and Jeong (2014), Jambor and Leitão (2016).

The organisation of paper as follow: Section 2 presents the empirical modelling. Section 3 relates to data. The empirical results are presented in Section 4, followed by the conclusion in Section 5.

\section{Empirical Modelling}

In order to estimate the effect of IPRs protection on bilateral trade flows empirically, we construct gravity models on international trade. The gravity model has been used successfully by numerous researchers (Smith, 1999; Fink and Braga, 2005; Rafiquzzaman, 2002; Catherine, 2004) to empirically model the relationship between IPRs protection and trade flows. We follow Al-Mawali $(2005,2011)$ in adopting the gravity model, but extend the study in several way. Firstly, we employ the most recent data and use a much longer time period in our study (from 2010 to 2016) and secondly, we use UK horizontal and vertical IIT data, and thirdly, we extend the analysis by employing the GMM-SYS. Furthermore, our study focuses on an industry-specific IIT: machinery and transport equipment (identified with the 7 SITC $^{1}$ ).

The basic specifications for the augmented gravity models employed in this study are as follows:

$$
\begin{aligned}
\ln \left(I I T_{i j t}\right)= & \beta_{0}+\beta_{1} \ln \left(G D P_{i t} * G D P_{j t}\right)+\beta_{2} \ln \left(D_{i j}\right)+\beta_{3} \ln \left(T I_{i j t}\right)+\beta_{4} \ln \left(T B_{j t}\right)+ \\
& \beta_{5}\left(I P R_{j t}\right)+\beta_{6}\left(I M I T_{j t}\right)+\varepsilon_{\mathrm{ijt}}
\end{aligned}
$$

\footnotetext{
${ }^{1}$ SITC is the Standard International Trade Classification which is a statistical classification of the products entering external trade. The current international standard is the SITC, Revision 3.
} 


$$
\begin{aligned}
\ln \left(H I I T_{i j t}\right)= & \beta_{0}+\beta_{1} \ln \left(G D P_{i t} * G D P_{j t}\right)+\beta_{2} \ln \left(D_{i j}\right)+\beta_{3} \ln \left(T I_{i j t}\right)+\beta_{4} \ln \left(T B_{j t}\right)+ \\
& \beta_{5}\left(I P R_{j t}\right)+\beta_{6}\left(I M I T_{j t}\right)+\varepsilon_{\mathrm{ijt}} \\
\ln \left(V I I T_{i j t}\right)= & \beta_{0}+\beta_{1} \ln \left(G D P_{i t} * G D P_{j t}\right)+\beta_{2} \ln \left(D_{i j}\right)+\beta_{3} \ln \left(T I_{i j t}\right)+\beta_{4} \ln \left(T B_{j t}\right)+ \\
& \beta_{5}\left(I P R_{j t}\right)+\beta_{6}\left(I M I T_{j t}\right)+\varepsilon_{\mathrm{ijt}},
\end{aligned}
$$

where the subscript $i$ indicates the UK, the subscript $j$ indicates the UK's trading partners, and the subscript $t$ is time. IIT $T_{i j t}$ is the value of bilateral IIT between country $i$ (UK) and country $j$ in year $t$, where $H_{I I T} T_{i j t}$ and $V I I T_{i j t}$ refer to the value of bilateral HIIT and VIIT between country $i(\mathrm{UK})$ and country $j$ in year $t$, respectively. Other gravitational variables, which appear as independent variables in the models, are: $G D P_{i t}$ * GDP $P_{j t}$ is the Gross Domestic Products of country $i(\mathrm{UK})$ and country $j ; D_{i j}$ is the geographical distance between country $i$ (UK) and country $j$; $T I_{i j t}$ is trade intensity between country $i(\mathrm{UK})$ and country $j ; T B_{j t}$ is the trade barriers of country $j ; I P R_{j t}$ and $I M I T_{j t}$ are the IPRs and imitation ability of country $j$, respectively, and $\varepsilon_{i j t}$ is the error term. The sources of data for $G D P, D_{i j}, T I_{i j t}$ and $T B_{j t}$ are discussed in Section 3.

We then re-estimate equations (1) to (3) by including variables that describe the interaction effect between IPRs and the threat of imitation. The UK's trading partners are divided into three classifications concerning their threat of imitation: weak, moderate, and strong. This distinction is derived from the strength of IPRs protection in the trading countries and also their imitative ability (IMIT). The strength of IPRs protection in different countries is measured by the Ginarte and Park (1997) Index of IPR (GP Index). We used the most updated index from Park (2008). The IMIT is measured by considering research and development (R\&D) expenditures as a percentage of GDP. Data on R\&D expenditures were obtained from the UNESCO Institute for Statistics (2016).

According to Smith (1999) and Al-Mawali (2005), a country has strong IPRs protection if the GP Index is between 3 and 5; and, conversely, a country has weak IPRs protection if the GP Index is between 0 and 2. A country has a strong IMIT if the percentage of R\&D expenditure to GDP is greater than or equal to $0.5 \%$. A weak IMIT is when the percentage is less than 0.5 . A country that falls between these two measures

\begin{tabular}{|c|c|c|c|c|}
\hline Threat of Imitation & Weak $(W)$ & Moc & $(M)$ & Strong $(S)$ \\
\hline IPRs & Strong & Strong & Weak & Weak \\
\hline Imitative abilities (IMIT) & Weak & Strong & Weak & Strong \\
\hline
\end{tabular}
is considered to possess a moderate imitation threat. The following table summarises the classifications of the threats of imitation.

Table 1: The classifications of the threats of imitation.

Based on the above three threats of imitation classifications, we create a set of three dummy variables: $S$ for a strong imitation threat, $M$ for a moderate imitation treat and $W$ for a weak imitation threat. Each of these dummy variables interacts with the IPRs variable producing $S_{j t}{ }^{*} I P R_{j t}, M_{j t}{ }^{*} I P R_{j t}$ and $W_{j t}{ }^{*} I P R_{j t}$. When the three interaction 
variables, i.e., equations (1) to (3) are added into the gravity models, they indicate the UK's IIT flows' sensitivity to the strength of IPRs, within each threat of imitation class:

$$
\begin{aligned}
\ln \left(I I T_{i j t}\right)= & \beta_{0}+\beta_{1} \ln \left(G D P_{i t} * G D P_{j t}\right)+\beta_{2} \ln \left(D_{i j}\right)+\beta_{3} \ln \left(T I_{i j t}\right)+\beta_{4} \ln \left(T B_{j t}\right)+ \\
& \beta_{5} W_{j t}\left(I P R_{j t}\right)+\beta_{6} M_{j t}\left(I P R_{j t}\right)+\beta_{7} S_{j t}\left(I P R_{j t}\right)+\varepsilon_{\mathrm{ijt}} \\
\ln \left(H I I T_{i j t}\right)= & \beta_{0}+\beta_{1} \ln \left(G D P_{i t} * G D P_{j t}\right)+\beta_{2} \ln \left(D_{i j}\right)+\beta_{3} \ln \left(T I_{i j t}\right)+\beta_{4} \ln \left(T B_{j t}\right)+ \\
& \beta_{5} W_{j t}\left(I P R_{j t}\right)+\beta_{6} M_{j t}\left(I P R_{j t}\right)+\beta_{7} S_{j t}\left(I P R_{j t}\right)+\varepsilon_{\mathrm{ijt}} \\
\ln \left(V I I T_{i j t}\right)= & \beta_{0}+\beta_{1} \ln \left(G D P_{i t} * G D P_{j t}\right)+\beta_{2} \ln \left(D_{i j}\right)+\beta_{3} \ln \left(T I_{i j t}\right)+\beta_{4} \ln \left(T B_{j t}\right)+ \\
& \beta_{5} W_{j t}\left(I P R_{j t}\right)+\beta_{6} M_{j t}\left(I P R_{j t}\right)+\beta_{7} S_{j t}\left(I P R_{j t}\right)+\varepsilon_{\mathrm{ijt}} \cdot
\end{aligned}
$$

In order to tackle any unobserved heterogeneity of country specific trade flows, the panel structure of the data was exploited previously in the literature by resorting to fixed or random effects methodology. Unfortunately, the fixed effects model suffers from two important defects. Firstly, it drops all time-invariant variables out of the model. Secondly, the fixed effects approach only uses variations within countries, ignoring any variation between countries in the sample (the differences in the levels of variables across countries). It is useful when the unobservable individual-specific effects $\varepsilon_{i}$ are fixed but not common across countries. Examination of the data shows that all of the variables, except for the trade barriers variable, have more between country variability than within country variability. However, in order to ensure robustness in the results, this study employs both fixed and random effects methodology.

\section{Data description and sources}

For the purpose of our investigation, cross-sectional data were collected on the trade flows between the countries that the UK trades with on different continents, including Canada, USA, Japan, China, France, Germany, Australia, and New Zealand.

The data for the dependent variables, IIT, HIIT and VIIT, were obtained from the United Nations Trade Data and focussed on the trade of machinery and transport equipment (identified with the 7 SITC) at four-digits, between the UK and its major trading partners. We use Kandogan's methodology (2003a) to separate IIT into the components: HIIT and VIIT. Kandogan's methodology is summarised as follows: $T T_{i}=X_{i}-M_{i}$, where $T T_{i}$ is total trade, $X_{i}$ is the monetary value of exports and $M_{i}$ is the monetary value of imports. The IIT is given by $I I T_{i}=T T_{i}-\left|X_{i}-M_{i}\right|$, the interindustry trade is $I N T_{i}=T T_{i}-I I T_{i}$, and the HIIT is $H I I T_{i}=\sum\left(X_{i k}+M_{i k}-\left|X_{i k}-M_{i k}\right|\right)$. Thus, VIIT is $V I I T_{i}=I I T_{i}-H I I T_{i}$. Figure 1 shows the evolution of UK's IIT, HIIT, and VIIT with trading partner countries over the studied period. 

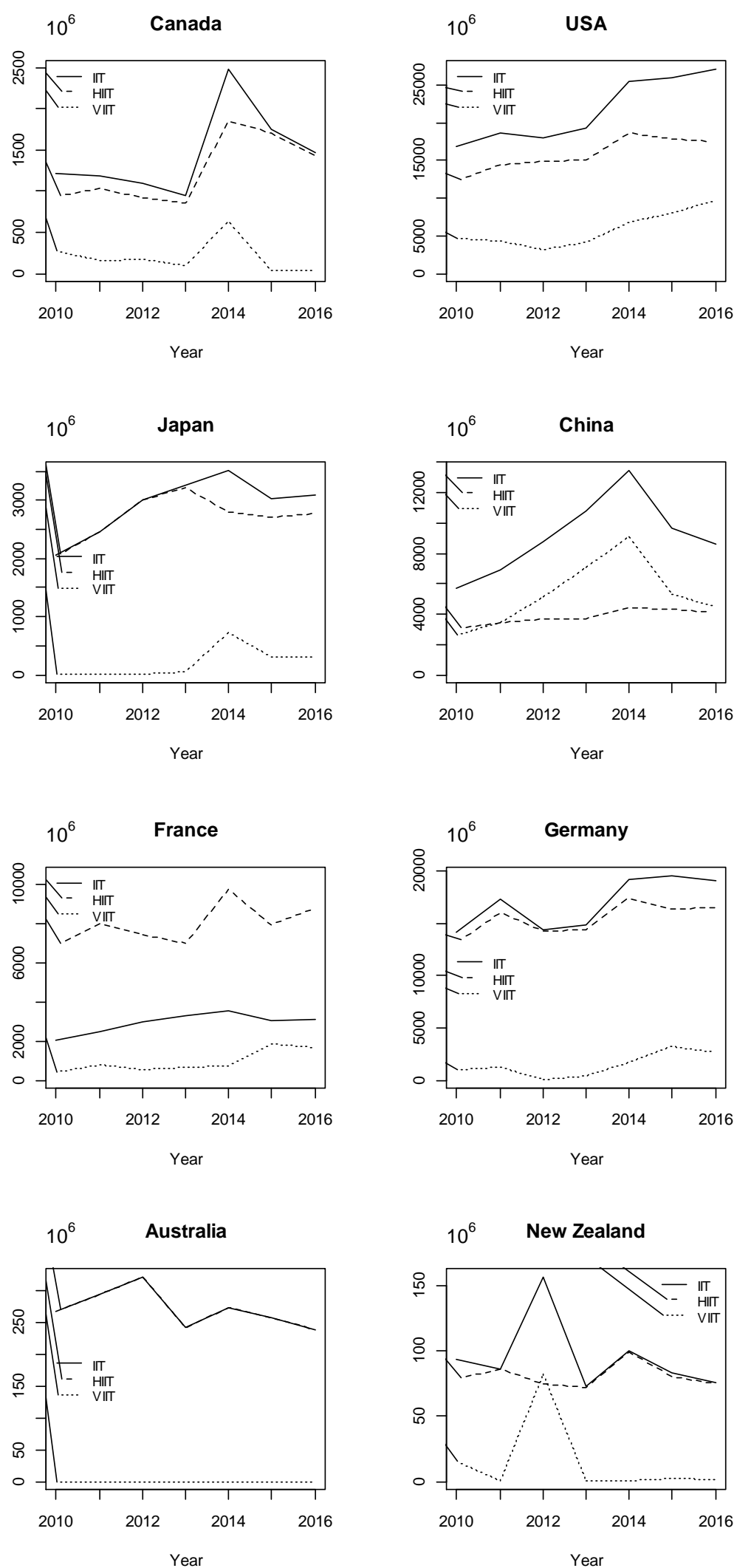

Figure 1. The evolution of the UK's IIT, HIIT, and VIIT with trading partner countries over the period 2010-2016, focussing on the trade of machinery and transport equipment. 
The basic gravitational variables, which appear as independent variables in this study, include: the per capita GDP of the UK and its trading partners as a proxy for the market's size $\left(G D P_{i t} * G D P_{j t}\right)$ in US dollars, where the data were obtained from the World Bank (2016). Geographical distance $D_{i j}$ data were calculated using the same method as Rose (2000) - an algorithm known as the Great Circle distance, where we use a Movable Type Scripts' calculator. Other independent variables are trade intensity $T I_{i j t}$ and trade barriers $T B_{j t}$ which are important factors in determining the UK's IIT. $T I_{i j t}$ was calculated as $T I_{i j t}=\frac{\left(x_{i j t} / X_{i t}\right)}{\left(x_{w j t} / X_{w t}\right)}$, where $x_{i j t}$ is the monetary value of country $i$ 's (UK) exports country $j, x_{w j t}$ is the total monetary value of the world exports to country $j, X_{i t}$ is the monetary value of the exports of country $i$ to the world, and $X_{w t}$ is the total monetary value of world exports. The trade data were obtained from the United Nations Commodity Trade Statistics Database (UN Comtrade Database, 2016). In order to measure $T B_{j t}$, we use average tariff rates as a proxy. Data for this variable are available from the database of the UNCTAD-Trade Analysis and Information System (TRAINS).

\section{Estimation Results}

\subsection{Generalised Least Squares (GLS) random and fixed effects regression}

The estimation results for the GLS random and fixed effects regression for equations (1) to (3) are reported in Table 2, and for equations (4) to (6) are reported in Table 3.

Table 2: Estimation results of GLS random and fixed effects regressions for equations (1) to (3).

\begin{tabular}{|c|c|c|c|c|c|c|}
\hline \multirow[b]{2}{*}{ Variables } & \multicolumn{2}{|c|}{ IIT } & \multicolumn{2}{|c|}{ HIIT } & \multicolumn{2}{|c|}{ VIIT } \\
\hline & $\begin{array}{l}\text { GLS random } \\
\text { effects }\end{array}$ & $\begin{array}{l}\text { Fixed } \\
\text { effects }\end{array}$ & $\begin{array}{l}\text { GLS random } \\
\text { effects }\end{array}$ & $\begin{array}{l}\text { Fixed } \\
\text { effects }\end{array}$ & $\begin{array}{l}\text { GLS random } \\
\text { effects }\end{array}$ & $\begin{array}{l}\text { Fixed } \\
\text { effects }\end{array}$ \\
\hline \multirow[t]{2}{*}{ Constant } & -9.652 & -4.681 & 2.121 & 5.563 & 7.584 & 9.83667 \\
\hline & $(-0.93)$ & $(-0.40)$ & $(0.26)$ & $(0.64)$ & $(0.89)$ & (0.79) \\
\hline \multirow{2}{*}{$G D P_{i t} * G D P_{j t}$} & 0.701 & 0.452 & 0.510 & 0.269 & 0.619 & 0.894 \\
\hline & $(4.14)^{* * *}$ & $(2.14) * *$ & $(3.89)^{* * *}$ & $(1.71)^{*}$ & $(2.87)^{* * *}$ & $(2.33)^{* *}$ \\
\hline \multirow[t]{2}{*}{$D_{i j}$} & -1.025 & Dropped $^{+}$ & -1.159 & Dropped $^{+}$ & -1.549 & Dropped $^{+}$ \\
\hline & $(-2.64)^{* * *}$ & & $(-3.86) * * *$ & & $(-0.68)$ & \\
\hline \multirow[t]{2}{*}{$T I_{i j t}$} & 0.6202 & 0.728 & 0.215 & 0.312 & 1.230 & 1.347 \\
\hline & $(2.80)^{* * *}$ & $(3.14) * * *$ & (1.26) & $(1.81)^{*}$ & $(0.86)$ & (0.89) \\
\hline \multirow[t]{2}{*}{$T B_{j t}$} & -0.034 & -0.0270 & -0.196 & -0.259 & -1.138 & -0.089 \\
\hline & $(-2.02)^{* *}$ & $(-2.06)^{* *}$ & $(-1.52)$ & $(-2.04) * *$ & $(-2.71)^{* * *}$ & $(-1.87)^{*}$ \\
\hline \multirow[t]{2}{*}{$I M I T_{j t}$} & -0.070 & -0.005 & -0.066 & -0.0422 & -0.681 & 0.895 \\
\hline & $(-0.26)$ & $(-0.02)$ & $(-0.31)$ & $(-0.18)$ & $(0.96)$ & $(0.37)$ \\
\hline \multirow[t]{2}{*}{$I P R_{j t}$} & 0.063 & 0.145 & 0.143 & 0.204 & -0.263 & -0.127 \\
\hline & $(0.93)$ & $(1.02)$ & $(1.28)$ & $(1.71)^{*}$ & $(-0.27)$ & $(-0.12)$ \\
\hline R-square & 0.878 & 0.719 & 0.877 & 0.651 & 0.718 & 0.652 \\
\hline
\end{tabular}

Note: $z$-statistics for the GLS random effects model and the corresponding $t$-statistics for the fixed effects model are given in parentheses. An asterisk (*) indicates the given variable is statistically significant up to a $10 \%$ level of significance, $* *$ for $5 \%$ and $* * *$ for $1 \%$ level of significance. ${ }^{+}$the fixed effects model automatically drops out all time-invariant variables from the model.

Table 3: Estimation results of GLS random and fixed effects regressions for equations (4) to (6). 


\begin{tabular}{|c|c|c|c|c|c|c|}
\hline \multirow[b]{2}{*}{ Variables } & \multicolumn{2}{|c|}{ IIT } & \multicolumn{2}{|c|}{ HIIT } & \multicolumn{2}{|c|}{ VIIT } \\
\hline & $\begin{array}{c}\text { GLS random } \\
\text { effects }\end{array}$ & $\begin{array}{l}\text { Fixed } \\
\text { effects }\end{array}$ & $\begin{array}{c}\text { GLS random } \\
\text { effects }\end{array}$ & $\begin{array}{l}\text { Fixed } \\
\text { effects }\end{array}$ & $\begin{array}{c}\text { GLS random } \\
\text { effects }\end{array}$ & $\begin{array}{l}\text { Fixed } \\
\text { effects }\end{array}$ \\
\hline \multirow[t]{2}{*}{ Constant } & -24.524 & -5.353 & -16.916 & 2.1610 & 27.349 & 32.733 \\
\hline & $(-4.10) * * *$ & $(-0.43)$ & $(-3.02) * * *$ & $(0.23)$ & (1.23) & $(0.41)$ \\
\hline \multirow{2}{*}{$G D P_{i t} * G D P_{j t}$} & 0.9313 & 0.476 & 0.812 & 0.348 & 0.652 & 0.4886 \\
\hline & $(8.90) * * *$ & $(2.17)^{* *}$ & $(8.32) * * *$ & $(2.08) * *$ & $(1.71)^{*}$ & $(0.34)$ \\
\hline$D_{i j}$ & $\begin{array}{r}-0.895 \\
(-8.28)^{* * * *}\end{array}$ & Dropped $^{+}$ & $\begin{array}{r}-0.981 \\
(-9.10) * * *\end{array}$ & Dropped $^{+}$ & $\begin{array}{r}-1.755 \\
(-3.41)^{* * * *}\end{array}$ & Dropped $^{+}$ \\
\hline \multirow[t]{2}{*}{$T I_{i j t}$} & 0.530 & 0.729 & 0.253 & 0.321 & 0.308 & 1.431 \\
\hline & $(2.55)^{* *}$ & $(3.13)^{* * *}$ & (1.44) & $(1.80)^{*}$ & $(0.14)$ & $(0.95)$ \\
\hline \multirow[t]{2}{*}{$T B_{j t}$} & -0.029 & -0.062 & -0.143 & -0.300 & -0.7147 & -1.2106 \\
\hline & $(-1.84)^{*}$ & $(-0.36)$ & $(-0.93)$ & $(-2.28) * *$ & $(0.33)$ & (1.79)* \\
\hline \multirow{2}{*}{$W_{j t} * I P R_{j t}$} & 0.812 & 0.765 & 0.456 & -0.197 & 1.120 & 0.963 \\
\hline & $(0.75)$ & $(0.95)$ & (1.07) & $(0.48)$ & $(0.47)$ & $(0.88)$ \\
\hline \multirow[t]{2}{*}{$M_{j t} * I P R_{j t}$} & 0.269 & -0.166 & 0.265 & -0.213 & 0.490 & 0.319 \\
\hline & $(1.79) *$ & $(-0.46)$ & $(2.12)^{* *}$ & $(-0.76)$ & $(1.86)^{*}$ & $(1.82)^{*}$ \\
\hline \multirow{2}{*}{$S_{j t} * I P R_{j t}$} & 0.763 & 0.746 & 0.405 & -0.168 & 1.065 & 0.948 \\
\hline & $(1.80)^{*}$ & $(0.27)$ & $(1.94)^{*}$ & $(-0.08)$ & $(0.54)$ & $(0.61)$ \\
\hline R-square & 0.859 & 0.564 & 0.869 & 0.722 & 0.695 & 0.418 \\
\hline
\end{tabular}

Note: $z$-statistics for the GLS random effects model and the corresponding $t$-statistics for the fixed effects model are given in parentheses. An asterisk (*) indicates the given variable is statistically significant up to a $10 \%$ level of significance, $* *$ for $5 \%$ and $* * *$ for $1 \%$ level of significance. ${ }^{+}$the fixed effects model automatically drops out all time-invariant variables from the model.

As shown in Tables 2 and 3, the overall performance of the gravity models for the total IIT and its two components (HIIT and VIIT) are quite satisfactory in terms of statistical significance. In addition, economic interpretations, with $R$-squared, vary from $69.5 \%$ to $87.8 \%$, except for fixed effects for VIIT, as shown in Table 3.

The results show that the market size, proxied by multiplying the GDP of the UK by the GDP of its trading partner $G D P_{i t} * G D P_{j t}$, is the most important determinant of total IIT and its components (HIIT and VIIT). The coefficients are positive and significant in almost all specifications. This implies that the UK tends to conduct more of its total IIT, both HIIT and VIIT, with larger economic sizes.

Earlier literature, such as Krugman (1980) and Balassa (1986), found that the volume of IIT is negatively correlated with geographical distance. Distance increases the transaction costs associated with shipping and insurance, therefore this has an expected negative impact on the value of IIT. Our results are consistent with previous studies and show that the geographical distance $D_{i j}$ has a negative and significant relationship with IIT and its components (HIIT and VIIT).

The coefficients of the trade intensity $T I_{i j t}$ are positive and are statistically significant for the case of IIT (using both GLS random and fixed effects models) and HIIT (using fixed effects model). This empirically indicates that the stronger the trade intensity between the UK and its trading partners, the larger the volume of the UK's IIT and its components (HIIT and VIIT).

The results show that the coefficients for trade barriers $T B_{j t}$ are negative and statistically significant in most specifications, as shown in Tables 2 and 3. This demonstrates that the higher the trade barriers imposed by the UK's trading partners, 
the smaller the volume of the UK's total IIT and both its components. This is consistent with the findings of Drabek and Greenaway (1984) that total IIT and both of its components are negatively related to the strength of the trade barriers.

Table 2 shows that the coefficients for $I M I T_{j t}$ are negative in almost all specifications, but are statistically insignificant in all specifications. This means that imitative ability, per se, is not an important factor in determining IIT flows between the UK and its trading partners. The positive sign for the $I P R_{j t}$ variable (except for VIIT) would indicate the variable is positively correlated with IIT flows, including both market expansion (i.e., demand-side effects), and increase in supply (i.e., supply-side effects). The insignificant estimates of $I P R_{j t}$, in almost all specifications, would suggest the IPRs are not related to IIT. In general, these results suggest that both IMIT and IPRs, separately, are not important factors in determining the IIT flows between the UK and its trading partners. This result is consistent with other studies such as Al-Mawali (2005).

Regarding the interaction between IPRs and the threat of imitation dummies $S_{j t}{ }^{*} I P R_{j t}, M_{j t}{ }^{*} I P R_{j t}$ and $W_{j t}{ }^{*} I P R_{j t}$ as shown in Table 3, the results show that there is a statistically insignificant relationship between the strength of foreign IPRs and the UK's IIT across countries with weak imitative abilities in all regressions, except for the HIIT. This implies that there are market expansion effects on IPRs for countries with weak imitative abilities.

The relationship between the strength of foreign IPRs and the UK's IIT, across countries with moderate and strong imitative abilities, is positive and statistically insignificant in most of the regressions. However, the results are positive and statistically significant in the case of the GLS random effects estimation of IIT and HIIT. This implies that there is a market expansion effect on IPRs, across countries with moderate and strong imitation threats, in the case of IIT and HIIT. These results are also in line with other similar studies, such as Smith's (1999). The empirical results also confirm that, in general, IPRs and IMIT variables jointly are determents to the general flows of the UK's IIT.

\subsection{Generalised Method of Moments (GMM) for dynamic panel model}

We extend the analysis by employing the GMM-SYS following Areliano and Bover (1995) and Blundell and Bond (1998), for the dynamic panel model in order to solve the problems of non-stationarity and the endogeneity of some variables that could emerge for the panel data. The GMM-SYS has become an important tool in the empirical analyses of panels with a large number of individual units and relatively short time series. Prior to the estimation, we conducted an augmented Dickey-Fuller-Fisher (ADF-Fisher) inverse chi-squared, Levin-Lin-Chu and Im-Pesaran-Shin tests for unit roots on these variables. The results are reported in Table 4.

Table 4: Unit root tests results. 


\begin{tabular}{lccc}
\hline \multicolumn{1}{c}{ Variables } & $\begin{array}{c}\text { ADF inverse } \\
\text { chi-squared }\end{array}$ & Levin-Lin-Chu & Im-Pesaran-Shin \\
\hline IIT & $22.2280(0.0315)$ & $-0.3028(0.0012)$ & $-1.0210(0.0000)$ \\
HIIT & $27.9301(0.0175)$ & $-6.0106(0.0000)$ & $-1.7518(0.0039)$ \\
VIIT & $39.0656(0.0000)$ & $-2.0311(0.0000)$ & $-0.3130(0.0000)$ \\
$G D P_{i t} * G D P_{j t}$ & $29.0463(0.0105)$ & $-0.0803(0.0000)$ & $-1.6950(0.0000)$ \\
$D_{i j}$ & n.a. & n.a. & n.a. \\
$T I_{i j t}$ & $68.8076(0.0000)$ & $-17.4024(0.0000)$ & $-0.8205(0.0000)$ \\
$T B_{j t}$ & $6.0971(0.6650)$ & $-0.9797(0.1636)$ & n.a. \\
$I P R_{j t}$ & $9.6248(0.0460)$ & n.a. & n.a. \\
$I M I T_{j t}$ & $57.5818(0.0000)$ & n.a. & n.a. \\
\hline
\end{tabular}

Note: Adjusted $t$-statistics are reported with $p$-values in parentheses.

The results show that almost all the series are stationary, at a 5\% significance level, except for the variable $T B_{j t}$. In general, we conclude that the panel is likely to be stationary.

The estimated results for equations (1) to (3) and for equations (4) to (6), using the GMM-SYS one-step and two-step models are shown in Tables 5 and 6, respectively. The Sargan tests of the over identifying restrictions for the two-step GMM-SYS show that there are no concerns with the validity of the instruments used. Results are quite similar for the two methods. The two-step GMM-SYS estimates with correction for heteroskedasticity basically confirm the first-step findings.

Table 5: Estimation results of GMM-SYS for equations (1) to (3).

\begin{tabular}{|c|c|c|c|c|c|c|}
\hline & \multicolumn{2}{|c|}{ IIT } & \multicolumn{2}{|c|}{ HIIT } & \multicolumn{2}{|c|}{ VIIT } \\
\hline & one-step & two-step & one-step & two-step & one-step & two-step \\
\hline \multirow[t]{2}{*}{ Constant } & 0.269 & 0.311 & 0.205 & 0.217 & 0.361 & 0.363 \\
\hline & (1.34) & (1.41) & $(1.25)$ & (1.32) & $(-2.13)^{* *}$ & $(-2.10)^{* *}$ \\
\hline \multirow{2}{*}{$G D P_{i t} * G D P_{j t}$} & 0.571 & 0.563 & 0.566 & 0.472 & 0.589 & 0.573 \\
\hline & $(1.70)^{*}$ & $(1.72)^{*}$ & $(2.42)^{* *}$ & $(2.29) * *$ & $(1.85)^{*}$ & $(1.71)^{*}$ \\
\hline \multirow[t]{2}{*}{$D_{i j}$} & -0.456 & -0.381 & -0.575 & -0.491 & -0.460 & -0.311 \\
\hline & $(-2.32)^{* *}$ & $(-2.09)^{* *}$ & $(-2.88) * * *$ & $(-2.42)^{* *}$ & $(-2.15)^{* *}$ & $(-1.94) *$ \\
\hline \multirow[t]{2}{*}{$T I_{i j t}$} & 0.877 & 0.898 & 0.228 & 0.123 & 0.414 & 0.397 \\
\hline & $(3.05) * * *$ & $(3.03) * * *$ & (1.19) & (0.98) & $(2.09) * *$ & $(2.01)^{* *}$ \\
\hline \multirow[t]{2}{*}{$T B_{j t}$} & -0.271 & -0.262 & -0.252 & -0.244 & -0.372 & -0.312 \\
\hline & $(-2.33)^{* *}$ & $(-2.31)^{* *}$ & $(-2.41) * *$ & $(-2.39)^{* *}$ & $(2.68)^{* * *}$ & $(2.59) * * *$ \\
\hline \multirow[t]{2}{*}{$I M I T_{j t}$} & 0.236 & 0.101 & 0.049 & 0.035 & 0.407 & 0.392 \\
\hline & $(0.54)$ & $(0.24)$ & $(0.15)$ & $(0.08)$ & $(0.86)$ & $(0.71)$ \\
\hline \multirow[t]{2}{*}{$I P R_{j t}$} & 0.002 & 0.002 & -0.008 & -0.008 & -0.147 & -0.127 \\
\hline & $(0.01)$ & $(0.01)$ & $(-0.06)$ & $(-0.05)$ & $(-0.13)$ & $(-0.04)$ \\
\hline Sargan test & & 0.341 & & 0.458 & & 0.542 \\
\hline
\end{tabular}

Note: An asterisk (*) indicates the given variable is statistically significant up to a $10 \%$ level of significance, $* *$ for $5 \%$ and $* * *$ for $1 \%$ level of significance.

Table 6: Estimation results of GMM-SYS for equations (4) to (6).

\begin{tabular}{lcrrrrr}
\hline & \multicolumn{2}{c}{ IIT } & \multicolumn{2}{c}{ HIIT } & \multicolumn{2}{c}{ VIIT } \\
\cline { 2 - 7 } & \multicolumn{1}{c}{ one-step } & two-step & one-step & two-step & one-step & two-step \\
\hline Constant & -0.056 & -0.091 & 0.225 & 0.513 & -0.368 & 0.453 \\
& $(-0.33)$ & $(-0.42)$ & $(1.43)$ & $(1.63)$ & $(-2.20)^{* *}$ & $(-2.31)^{* *}$
\end{tabular}




$\begin{array}{lrrrrrr}G D P_{i t} * G D P_{j t} & 0.623 & 0.609 & 0.799 & 0.592 & 0.667 & 0.511 \\ D_{i j} & (1.77)^{*} & (1.99)^{* *} & (2.48)^{* *} & (1.92)^{*} & (1.82)^{*} & (1.73)^{*} \\ & -0.255 & -0.192 & -0.232 & -0.224 & -0.195 & -0.104 \\ T I_{i j t} & (-2.94)^{* * *} & (-2.51)^{* *} & (2.88)^{* * *} & (2.47)^{* *} & (-2.01)^{* *} & (-1.93)^{*} \\ & 0.867 & 0.521 & 0.221 & 0.203 & 0.687 & 0.263 \\ T B_{j t} & (3.04)^{* * *} & (2.98)^{* * *} & (1.17) & (1.05) & (2.30)^{* *} & (1.88)^{*} \\ W_{j t} * I P R_{j t} & 0.208 & 0.115 & -0.257 & -0.182 & -0.282 & -0.268 \\ M_{j t} * I P R_{j t} & (0.96) & (0.83) & (-1.66)^{*} & (1.62) & (-2.67)^{* * *} & (-2.57)^{* *} \\ & 0.202 & 0.191 & 0.458 & 0.275 & 0.759 & 0.746 \\ S_{j t} * I P R_{j t} & (0.07) & (0.00) & (0.26) & (0.13) & (1.50) & (1.48) \\ & 0.458 & 0.290 & 0.523 & 0.511 & 0.621 & 0.593 \\ \text { Sargan test } & (0.86) & (0.13) & (1.63) & (1.60) & (1.73)^{*} & (1.63) \\ & 0.750 & 0.569 & 0.698 & 0.592 & 0.972 & 0.526 \\ & (1.73)^{*} & (1.62) & (1.68)^{*} & (1.66)^{*} & (0.68) & (0.55) \\ \end{array}$

Note: An asterisk $(*)$ indicates the given variable is statistically significant up to a $10 \%$ level of significance, $* *$ for $5 \%$ and $* * *$ for $1 \%$ level of significance.

The empirical results of the GYMM-SYS are generally consistent with the GLS random and fixed effects models. However, we notice that the relationship between the strength of foreign IPRs and the UK's IIT, across countries with moderate imitative abilities, becomes statistically insignificant, except for the VIIT. Despite the difference, we can still conclude that the GMM-SYS support the findings, as discussed in Section 4.

\section{Conclusion}

This study has attempted to answer three questions. Firstly, it asks to what extent is the UK's bilateral IIT, and its two components (HIIT and VIIT), sensitive to the national differences in foreign IPRs protection. Secondly, it asks whether the UK's bilateral IIT, and its two components, are related to its trading partners' threat of imitation variable. Finally, it investigates the relationship between the UK's bilateral IIT and IPRs, in relation to the threat of imitation and IPRs variables jointly.

We carried out an empirical investigation to answer the above three questions. The investigation was based on pooled UK data and benefitted from the theoretical distinction between the horizontal and vertical IIT, using Kandogan's (2003a) methodology for disentangling the total IIT into HIIT and VIIT. A gravity equation of international trade was estimated, using both fixed and random effects models. We also compared the results with the GMM-SYS for the dynamic panel.

The main findings are as follows: firstly, the estimated results of the basic gravity models, for the total IIT and its two components (HIIT and VIIT) are generally quite satisfactory in terms of their statistical significance and economic interpretation. Secondly, the UK's total IIT, and its two components depend neither on IPRs protection, per se, nor on the imitative ability of the UK's trading partners. Finally, the combined forces of both IPRs protection and imitative ability are important factors in determining 
the UK's IIT. This implies that the threat of imitation, as measured by IPRs and IMIT simultaneously, is a significant variable in determining IIT flows.

\section{References}

Al-Mawali, N. (2005). Bilateral intra-industry trade flows and intellectual property rights protection: first empirical evidence. Applied Economics Letters , 823-828.

Al-Mawali, N. (2011). Does the level of intellectual property rights have different effects on inter-and intra-industry trade? Investment Management and Financial Innovations, 8(4), 119-122.

Areliano, M., and Bover, O. (1995). Another look at the instrumental variable estimation of errorcomponents models. Journal of Econometrics, 68, 29-51.

Awokuse, T., and Yin, H. (2016). Does stronger intellectual property rights protection induce more bilateral trade? Evidence from China's imports. World Development, 1094-1104.

Balassa, B. (1986). The determinants of intra-industry specialization in United States trade. Oxford Economic Papers, 38(2), 220-233.

Blundell, R., and Bond, S. (1998). Initial conditions and moment restrictions in dynamic panel data models. Journal of Econometrics, 87(1), 115-143.

Catherine, C. (2004). Do patent rights regimes matter? Review of International Economics, 12(3), 359373.

Drabek, Z., and Greenaway, D. (1984). Economic integration and intra-industry trade: The EEC and CMEA compared. Kyklos, 37 (3), 444-469.

Faustino, H., and Leitão, N. (2007). The intra-industry trade between Portugal and European Union: A static and dynamic panel data analysis (1996-2000). International Advances in Economic Research, 13(3), 313-333.

Felbermayr, G. (2005). Dynamic panel data evidence on the trade-income relation. Review of World Economics, 141(4), 583-611.

Fink, C. and Braga, P. (2005). How Stronger Protection of Intellectual Property Rights Affects International Trade Flows, in Fink, C. and Maskus, K.E. (eds.), Intellectual Property and Development: Lessons from Recent Economic Research, The World Bank/Oxford University Press, Washington DC.

Fukase, E. (2010). Revisiting linkages between openness, education and economic growth: System GMM approach. Journal of Economic Integration, 193-222.

Ginarte, J., and Park, W. (1997). Determinants of patent rights: A cross-national study. Research Policy, 26(3), 283-301.

Helpman, E. (1981). International trade in the presence of product differentiation, economies of scale and monopolistic competition: A Chamberlin-Heckscher-Ohlin approach. Journal of International Economics, 11(3), 305-340.

Ivus, O. (2010). Do stronger patent rights raise high-tech exports to the developing world? Journal of International Economics, 81(1), 38-47.

Jambor, A., and Leitão, N. (2016). Industry-specific determinants of vertical intra-industry trade: the case of EU new member states' agri-food sector. Post-Communist Economies, 28(1), 34-48.

Kabir, M., and Salim, R. (2016). Is trade in electrical and electronic products sensitive to IPR protection? Applied Economics, 48(21), 1991-2005.

Kandogan, Y. (2003). Reconsidering the adjustment costs of the Europe agreements. Applied Economics Letters, 10(2), 63-68.

Kandogan, Y. (2003a). Intra-industry trade of transition countries: Trends and determinants. Emerging Markets Review, 4(3), 272-286.

Krugman, P. (1979). Increasing returns, monopolistic competition, and international trade. Journal of International Economics, 9, 469-479.

Krugman, P. (1980). Scale economics, product differentiation and the pattern of trade. American Economic Review, 70 (5), 950-959. 
Lancaster, K. (1980). Intra-industry trade under perfect monopolistic competition. Journal of International Economics, 10(2), 151-175.

Maskus, K., and Penubarti, M. (1995). How trade-related are intellectual property rights? Journal of International Economics, 39(3-4), 227-248.

Maskus, K., and Yang, L. (2013). The impacts of post-TRIPS patent reforms on the structure of exports. Tokyo: The Research Institute of Economy, Trade and Industry.

OECD. (2010). Measuring Globalisation: OECD Economic Globalisation Indicators. Paris: OECD Publishing.

Phan, H.T., and Jeong, Y.J. (2014). An empirical analysis of intra industry trade in manufactures between Korea and ASEAN. Journal of Economic Studies, 41(6), 833-848.

Park, W. (2008). International patent protection: 1960-2005. Research Policy, 37, 761-766.

Rafiquzzaman, M. (2002). Impact of patent rights on international trade: Evidence from Canada. The Canadian Journal of Economics, 35(2), 307-330.

Rose, A. (2000). One money, one market: Estimating the effects of common currencies on trade, Economic Policy, 15 (30), 7-45.

Salim, R., Al-Mawali, N., and Islam, A. (2014). Do the intellectual property rights of importers matter for promoting Australian exports? Australian Economic Review. 47 (3), 279-289.

Smith, P. (1999). Are weak patent rights a barrier to U.S. exports? Journal of International Economics, 48(1), 151-177.

Soukiazis, E., and Antunes, M. (2011). Is foreign trade important for regional growth? Empirical evidence from Portugal. Economic Modelling, 28(3), 1363-1373.

UN Comtrade Database. (2016). United Nations Commodity Trade Statistics Database. Retrieved 4 2016, 14 , from http://comtrade.un.org.

UNESCO Institute for Statistics. (2016). Gross domestic expenditure on R\&D (GERD), GERD as a percentage of GDP, GERD per capita and GERD per researcher. Retrieved 04 03, 2016.

World Bank. (2016). World Development Indictors. Retrieved May 5, 2016, from http://data.worldbank.org/data-catalog/world-development-indicators. 